\title{
Erratum to: Projection of future changes in the frequency of intense tropical cyclones
}

\author{
Masato Sugi $^{1}\left[\right.$ [D Hiroyuki Murakami ${ }^{1,2} \cdot$ Kohei Yoshida $^{1}$
}

Published online: 18 April 2017

(C) Springer-Verlag Berlin Heidelberg 2017

\section{Erratum to: Clim Dyn \\ DOI 10.1007/s00382-016-3361-7}

In the original publication of the article, Fig. 4 caption has been published incorrectly.

The correct Fig. 4 caption should be as follows:

The online version of the original article can be found under doi:10.1007/s00382-016-3361-7.

Masato Sugi

msugi@mri-jma.go.jp

1 Meteorological Research Institute, 1-1 Nagamine, Tsukuba,

Ibaraki, Japan

2 Geophysical Fluid Dynamics Laboratory, Princeton, NJ, USA 
(a) Cat 4-5

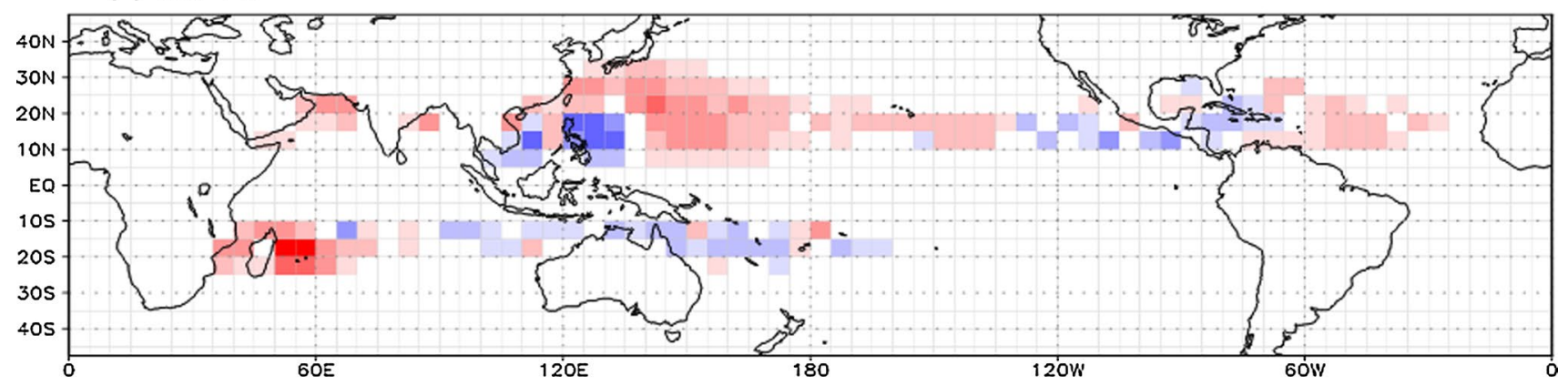

(b) Cat 3-5



(c) Cat 1-5

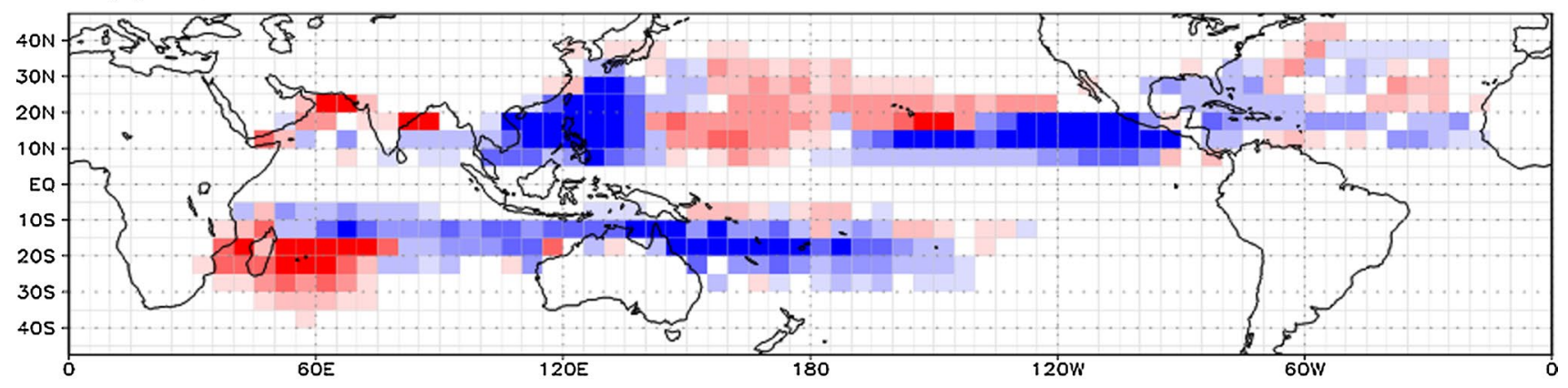

(d) Cat 0-5



Fig. 4 Changes in occurrence frequency (TC days) of tropical cyclones in various intensity categories. a Very intense tropical cyclones (cat 4-5), b major hurricanes (cat 3-5), c hurricane intensity storms (cat 1-5) and $\mathbf{d}$ all tropical storms (cat 0-5) 